NASA Technical Memorandum 101349

\title{
Phase Transformations in Xerogels of Mullite Composition
}

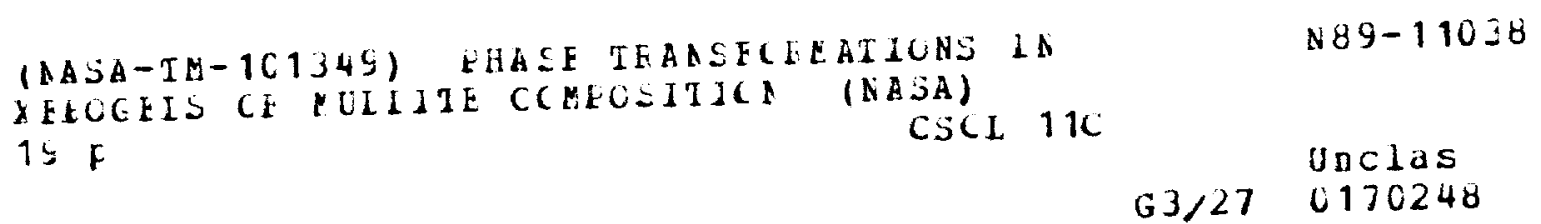

Mark J. Hyatt

Lewis Research Center

Cleveland, Ohio

and

Narottam P. Bansal

Case Western Reserve University

Cleveland, Ohio

Presented at the

89th Annual Meeting of the American Ceramic Society

Pittsburgh, Pennsylvania, April 26-30, 1987 
$\ldots$ 


\title{
PHASE TRANSFORMATIONS IN XEROGELS OF MULLITE COMPOSITION
}

\author{
Mark J. Hyatt \\ National Aeronautics and Space Administration \\ Lewis Research Center \\ Cleveland, Ohio 44135 \\ and \\ Narottam P. Bansal* \\ Case Western Reserve University \\ Cleveland, Ohio 44106
}

\section{SUMMARY}

Monophasic and diphasic xerogels have been prepared as precursors for mullite $\left(3 \mathrm{Al}_{2} \mathrm{O}_{3}-2 \mathrm{SiO}_{2}\right)$. Monophasic xerogel was synthesized from tetraethyl orthosilicate and aluminum nitrate nanohydrate and the diphasic xerogel from colloidal suspension of silica and boehmite. The chemical and structural evolutions, as a function of thermal treatment, in these two types of sol-gel derived mullite precursor powders have been characterized by DTA, TGA, x-ray diffraction, SEM and infrared spectroscopy. Monophasic xerogel transforms to an Al-Si spinel from an amorphous structure at $\sim 980^{\circ} \mathrm{C}$. The spinel then changes into mullite on further heating. Diphasic xerogel forms mullite at $\sim 1360^{\circ} \mathrm{C}$. The components of the diphasic powder react independently up to the point of mullite formation. The transformation in the monophasic powder occurs rapidly and yields strongly crystalline mullite with no other phases present. The diphasic powder, however, transforms rather slowly and contains remnants of the starting materials $\left(\alpha-\mathrm{Al}_{2} \mathrm{O}_{3}\right.$, cristobalite) even after heating at high temperatures for long times $\left(1600^{\circ} \mathrm{C}, 6 \mathrm{hr}\right)$. The diphasic powder could be sintered to high density but not the monophasic powder in spite of its molecular level homogeneity.

*NASA Resident Research Associate. 


\section{INTRODUCTION}

Mullite has been recognized as a promising material for high temperature structural applications because of its good mechanical strength, excellent thermal shock resistance, high creep resistance, low density, low thermal conductivity, and high temperature stability. Further gains are possible through improved processing or by addition of particulate, whisker, or fiber reinforcement. To accomplish these gains successfully, processing schemes compatible in temperature and pressure with available ceramic fibers need to be developed.

The objective of this work was to develop precursor materials which could be transformed into mullite and sintered at temperatures low enough to avoid fiber degradation during composite processing. Mono- and diphasic powders of stoichiometric mullite compositions have been synthesized by the sol-gel method and subjected to various thermal treatments. The chemical and structural evolutions taking place in these xerogels have been characterized by DTA, TGA, $x$-ray diffraction, SEM and infrared spectroscopy. Preliminary work on the sintering behavior of these powders has also been carried out.

\section{EXPERIMENTAL PROCEDURE}

Mono- and diphasic xerogel powders of stoichiometric mullite $\left(3 \mathrm{Al}_{2} \mathrm{O}_{3}-2 \mathrm{SiO}_{2}\right)$ composition were prepared by the procedures shown in the flowchart given in Fig. 1. The diphasic gel was prepared by dispersing boehmite (AlOOH) powder (Catapal D, Vista Chemicals or Disperal, Remet Corp.) in water using nitric acid as the peptizing agent $\left(1.0\right.$ meq $\left.\mathrm{H}+/ \mathrm{g} \mathrm{Al}_{2} \mathrm{O}_{3}\right)$. Colloidal silica (Ludox AS-40, DuPont) was then added to the boehmite

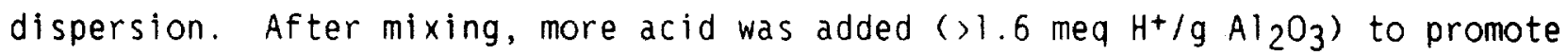
gelation. The mixture was then placed in a $70{ }^{\circ} \mathrm{C}$ water bath for evaporation of excess water and gelation. A white opaque gel was obtained. The monophasic 
gel was prepared by comixing reagent grade aluminum nitrate nanohydrate (Mallinkrodt) and tetraethoxysilane (TEOS, Alfa Products) in absolute ethyl alcohol. No additional water was added for hydrolysis as the water present in aluminum nitrate nanohydrate gave a water/TEOS mole ratio of $\sim 27$. The solution was placed in a $70^{\circ} \mathrm{C}$ water bath for evaporation of excess alcohol and hydrolysis and polymerization of TEOS. A clear, transparent gel was obtained. The gels were dried at $110^{\circ} \mathrm{C}$ for $72 \mathrm{hr}$ and ground to pass a 100 mesh screen. The chemical and structural evolutions, as a function of various thermal treatments, in mono- and diphasic xerogel powders were followed by several techniques. The thermogravimetric analysis (TGA) was carried out using a Perkin-Elmer TGS-2 system. Differential thermal analysis (DTA) was performed using a Perkin-Elmer DTA-1700. TGA and DTA runs were made at a heating rate of $10^{\circ} \mathrm{C} / \mathrm{min}$ in flowing air $(\sim 40 \mathrm{ml} / \mathrm{min})$. The crystalline phases were identified from powder $x$-ray diffraction (XRD). The XRD patterns were recorded using a Phillips ADP-3600 equipped with a crystal monochromator and $\mathrm{Cu} K$ radiation over the $2 \theta$ range from $10^{\circ}$ to $80^{\circ}$. The infrared absorption spectra (IRS) were recorded from 4000 to $450 \mathrm{~cm}^{-1}$ with a Perkin-Elmer 1750 FTIR interfaced with a 7300 data acquisition system. The IRS samples were prepared using the $\mathrm{KBr}$ pellet method.

After the initial characterization, approximately $100 \mathrm{~g}$ of each powder were heated in air in an electric furnace at $350^{\circ} \mathrm{C}$ for $50 \mathrm{hr}$. A sample of each powder was removed for analysis, and the remaining powder was heated at $490^{\circ} \mathrm{C}$ for $24 \mathrm{hr}$. Samples of each powder were again removed for analysis. Smaller samples of each powder after these two treatments were then used for the subsequent heat treatments. These powder samples were heated for $1 \mathrm{hr}$ at temperatures from 700 to $1600^{\circ} \mathrm{C}$. The heat treated powder samples were characterized by XRD and IRS. 
For preliminary sintering studies, dried mono- and diphasic gel powders were mixed with binder (2 percent Methocel and PVA, respectively) in aqueous solution, redried at $65^{\circ} \mathrm{C}$, and ground to pass a 100 mesh screen. The resulting powders were pressed into pellets under a pressure of $\sim 88 \mathrm{MPa}$ and sintered in air at various temperatures from 1200 to $1600{ }^{\circ} \mathrm{C}$ for 50 to $400 \mathrm{~min}$. The diphasic powder with Methocel was also dry pressed ( $42 \mathrm{MPa})$, then isostatically pressed $(\sim 414 \mathrm{MPa})$ into bars and sintered in air at 1350 or $1550{ }^{\circ} \mathrm{C}$ for 0.5 to $4 \mathrm{hr}$. Green densities were calculated from the weights and dimensions of the of the pellets and bars. Bulk and apparent densities of the sintered pellets and bars were measured using the Archimedes method. A thin layer of gold was evaporated on fracture surfaces of the sintered pellets and observed in a Cambridge 200 scanning electron microscope.

\section{RESULTS AND DISCUSSION}

TGA of the mono- and diphasic powders exhibits a two step weight loss for both, as shown in Fig. 2. The first step in both may be assigned to the loss of adsorbed water. In the monophasic powder the second step in weight loss involves the decomposition of the nitrate and oxidation of organics. The total weight loss of the monophasic xerogel amounts to $\sim 58$ percent. In the diphasic powder the second step in weight loss is due to the decomposition of boehmite. The total weight loss of the diphasic xerogel amounts to $\sim 20$ percent. There is little further weight change in either sample beyond $500{ }^{\circ} \mathrm{C}$.

DTA curves for mono- and diphasic powders are given in Figs. 3 and 4 , respectively. In both samples, two low temperature endothermic peaks are evident. The first peak is assigned to evaporation of water adsorbed in the micropores of the gels. The second peaks are due to decomposition of nitrate and oxidation of organics in the monophasic powder, and loss of adsorbed water followed by decomposition of boehmite in the diphasic sample. The temperatures 
where these peaks occur correspond to the weight losses noted in the TGA results. The strong exothermic peak at $\sim 975{ }^{\circ} \mathrm{C}$ in the curve for the monophasic gel may be attributed to the formation of an Al-Si spinel. This sharp crystallization peak indicates that $\mathrm{Si}-\mathrm{O}-\mathrm{Al}$ bonds were already formed during gelation in the precursor solution, eliminating the need for long-scale diffusion and bond rearrangement. This result is similar to that reported by Okada and Otsukal for their slow hydrolysis gel. In sol-gel processing from the metal alkoxides, hydrolys is results in mixed metal linkages via oxo-bridges and formation of hydrous oxide or the gel. Because these linkages are made at the molecular level, conversion of gel to crystalline oxides occurs at lower temperatures than required for conventional powder mixing techniques. In the DTA curve of diphasic xerogel, a small and broad exotherm over a wide temperature range is seen at $\sim 1360^{\circ} \mathrm{C}$. This may be assigned to the simultaneous crystallization of $\alpha-\mathrm{Al}_{2} \mathrm{O}_{3}$ and cristobalite and the formation of mullite by solid state reaction. Some reaction may occur between the phases before crystallization, as evidenced by the broad endotherm between 600 and $1100^{\circ} \mathrm{C}$. Thus, mullite formation occurs at a higher temperature and over a longer time in the diphasic xerogel. This result corresponds to those reported for similar materials by Hoffman et al. ${ }^{2}$ and Ismail et al. 3 The presence of ultrahomogeneous mixing on an atomic scale in the monophasic gels has been confirmed by Komarneni et al. ${ }^{4}$ using solid state ${ }^{27} \mathrm{Al}$ and ${ }^{29} \mathrm{Si}$ magic-angle spinning nuclear magnetic resonance (MASNMR) spectroscopy. The diphasic gels were found to be nano-heterogeneous. MASNMR spectra also showed the presence of $\mathrm{Al}$ in the immediate vicinity of $\mathrm{Si}$ in the monophasic gel but not in the diphasic gel.

The DTA results for the monophasic gel are quite similar to those for the metakaolinite to mullite transformation 5,6 where exothermic peaks were also 
observed at 960 and $1250{ }^{\circ} \mathrm{C}$. The exotherm at $960{ }^{\circ} \mathrm{C}$ was ascribed to the formation of mullite, Al-Si spinel, and amorphous $\mathrm{SiO}_{2}$. The spinel to mullite transformation was responsible for the $1250^{\circ} \mathrm{C}$ exotherm. The enthalpy change, $\Delta H$, corresponding to the $970^{\circ} \mathrm{C}$ exotherm in the DTA of monophasic gel was determined from the peak area for a sample which had been precalcined at $490{ }^{\circ} \mathrm{C}$. The value of $\Delta H$ for this peak was calculated to be $-166 \mathrm{~J} / \mathrm{g}$. In contrast, Hoffman et al. ${ }^{2}$ obtained a value of $-85 \mathrm{~J} / \mathrm{g}$ for a monophasic gel prepared in a similar way as in the present study. This low value is probably because their measurements were made for an uncalcined gel sample. On the other hand a value of $-250 \mathrm{~J} / \mathrm{g}$ has been reported by Sen and Thiagarajan 7 for a single-phase xerogel prepared from TEOS and aluminum s-butoxide.

The XRD patterns of the heat treated powders are given in Figs. 5 and 6 . Figure 5 shows that the monophasic powder is amorphous until heated to $1015{ }^{\circ} \mathrm{C}$. After I hr at this temperature, the powder contains mostly spinel phase and some mullite. When a sample is heated $1 \mathrm{hr}$ at $1150^{\circ} \mathrm{C}$, mullite becomes the major phase and the amount of spinel phase is reduced. The sample heated $1 \mathrm{hr}$ at $1250^{\circ} \mathrm{C}$ is predominantly mullite with a trace of the spinel phase. Above this temperature, the powder contains only mullite. It was first believed that xerogels formed by slow hydrolysis crystallize to mullite from the amorphous state. ${ }^{l}$ The spinel phase formed at $1015^{\circ} \mathrm{C}$ after 1 hr nearly disappears when the powder is heated at $1000{ }^{\circ} \mathrm{C}$ for $16 \mathrm{hr}$. This indicates that the spinel phase is the first to crystallize from the gel. The spinel is metastable and transforms easily to mullite by reaction with $\mathrm{SiO}_{2}$. This formation sequence has also been noted by Okada and Otsuka. 8

The sequence of phase development in the diphasic powder is very different as seen from Fig. 6. Until heated above the boehmite decomposition temperature, the pattern shows the starting materials, boehmite and amorphous 
silica. After $24 \mathrm{hr}$ at $490{ }^{\circ} \mathrm{C}$, the boehmite is transformed to a low temperature form of $\mathrm{Al}_{2} \mathrm{O}_{3}$ with a cubic spinel structure, and the amorphous phase is maintained. At $900{ }^{\circ} \mathrm{C}$, the pattern more closely resembles that of $\delta-\mathrm{Al}_{2} \mathrm{O}_{3}$, with the amorphous phase included. At $1150^{\circ} \mathrm{C}, \theta-\mathrm{Al}_{2} \mathrm{O}_{3}$ is seen along with the amorphous phase. In the sample heated at $1350^{\circ} \mathrm{C}$ for $1 \mathrm{hr}, \alpha-\mathrm{Al}_{2} \mathrm{O}_{3}$, cristobalite, and mullite are present. At $1450^{\circ} \mathrm{C}$, mullite, $\alpha-\mathrm{Al}_{2} \mathrm{O}_{3}$, and cristobalite are present in the same proportions as they were at $1350{ }^{\circ} \mathrm{C}$. However, the pattern shows a higher degree of crystallinity. At $1530{ }^{\circ} \mathrm{C}$, mullite predominates while the $\alpha-\mathrm{Al}_{2} \mathrm{O}_{3}$ and cristobalite amounts are reduced. After $1 \mathrm{hr}$ at $1600^{\circ} \mathrm{C}$, the major phase is mullite. $\alpha-\mathrm{Al}_{2} \mathrm{O}_{3}$ exists as a minor phase, and cristobalite has disappeared. No phases other than the cubic alumina spinel are seen prior to the formation of mullite and the other crystalline phases. Boehmite is known ${ }^{9}$ to have the following phase transformation sequence when annealed in air; it transforms into $\tau-\mathrm{Al}_{2} \mathrm{O}_{3}$ at $\sim 500{ }^{\circ} \mathrm{C}$, to $\delta-\mathrm{Al}_{2} \mathrm{O}_{3}$ around $850{ }^{\circ} \mathrm{C}$, to $\theta-\mathrm{Al}_{2} \mathrm{O}_{3}$ at $1050{ }^{\circ} \mathrm{C}$, and finally to $\alpha-\mathrm{Al}_{2} \mathrm{O}_{3}$ at $1150^{\circ} \mathrm{C}$. On the other hand the amorphous silica gel has a much simpler transformation to cristobalite at $\sim 1200^{\circ} \mathrm{C}$. The XRD results indicate that the constituents (boehmite and silica) of the diphasic xerogel behave independently until at high temperature when mullite is formed by reaction between $\alpha-\mathrm{Al}_{2} \mathrm{O}_{3}$ and cristobalite.

The structural changes occurring in the xerogels on firing at various temperatures were monitored by infrared spectroscopy. The infrared spectra of the heat treated monophasic and diphasic xerogel powders are given in Figs. 7 and 8. Figure 7 shows the IR spectra from 4000 to $450 \mathrm{~cm}^{-1}$ of the monophasic and diphasic powders, before and after the major decomposition reactions have taken place. The monophasic powder dried at $110^{\circ} \mathrm{C}$ exhibits strong absorption bands for water $\left(\sim 3450,1640 \mathrm{~cm}^{-1}\right)$ and nitrate $\left(1385 \mathrm{~cm}^{-1}\right)$. The principal band 
remaining after decomposition is a broad band near $1100 \mathrm{~cm}^{-1}$ due to the stretching modes of the silicon-oxygen network. In the diphasic powder dried at $110^{\circ} \mathrm{C}$, the principal absorption bands of boehmite ${ }^{10}$ are present. Also seen are bands attributable to amorphous silica $(1220,1078,800$, and $\left.460 \mathrm{~cm}^{-1}\right)$. The band due to nitrate is also present as a result of the nitric acid used to peptize the boehmite powder. After decomposition, the pattern obtained is similar to gamma alumina 10 with the amorphous silica still present. Figure 8 shows the spectra from 1400 to $450 \mathrm{~cm}^{-1}$ for the monophasic powder heated to 1150 and $1530{ }^{\circ} \mathrm{C}$ for $\mathrm{I} \mathrm{hr}$ and for the diphasic powder fired to 1350 and $1530^{\circ} \mathrm{C}$ for $1 \mathrm{hr}$. The difference between the patterns of the samples treated at low and high temperatures lies in the relation between the absorbances at 1130 and $1170 \mathrm{~cm}^{-1}$. At higher temperatures, the $1170 \mathrm{~cm}^{-1}$ band increases in intensity relative to the $1130 \mathrm{~cm}^{-1}$ band. This corresponds to a change in the chemical composition of the mullite from being rich in alumina towards the stoichiometric composition $(3: 2)$. Cameronll has reported the correlation between chemical compositions and absorbances of the $1130 \mathrm{~cm}^{-1}$ and $1170 \mathrm{~cm}^{-1}$ bands. The $1130 \mathrm{~cm}^{-1}$ band was stronger than the $1170 \mathrm{~cm}^{-1}$ band when the mullite was richer in $\mathrm{Al}_{2} \mathrm{O}_{3}$, and the reverse was true as the chemical composition of mullite approached $60 \mathrm{~mol} \% \mathrm{Al}_{2} \mathrm{O}_{3}$. Similar results have also been reported by Okada, et al. 12 Both samples heated at $1530{ }^{\circ} \mathrm{C}$ exhibit the principle absorption frequencies of mullite. 13 The spectra for the monophasic powder more closely matches the spectra obtained by Mackenzie.13 Residual crystalline phases in the diphasic material probably account for the discrepancies between its spectra and that of ideal mullite.13

Preliminary study was also carried out on the sintering behavior of the xerogel powders. The green density of dry pressed monophasic and diphasic pellets averaged 1.16 and $1.35 \mathrm{~g} / \mathrm{cm}^{3}$, respectively. The green density of cold 
isostatically pressed diphasic bars averaged $1.70 \mathrm{~g} / \mathrm{cm}^{3}$. The apparent and bulk densities of the diphasic bars sintered at 1350 and $1550^{\circ} \mathrm{C}$ for various lengths of time are shown in Fig. 9. Each point in the graph represents the average density for four bars. An average bulk density of $2.92 \mathrm{~g} / \mathrm{cm}^{3}(92.4$ percent theoretical) was obtained in bars which were sintered at $1550{ }^{\circ} \mathrm{C}$ for $4 \mathrm{hr}$. The bulk densities of dry pressed pellets which were sintered at $1600{ }^{\circ} \mathrm{C}$ for $400 \mathrm{~min}$ were only $2.69 \mathrm{~g} / \mathrm{cm}^{3}$ (85 percent theoretical) and $1.51 \mathrm{~g} / \mathrm{cm}^{3}$ (47.8 percent theoretical) for the diphasic and monophasic powders, respectively. This clearly demonstrates that it is much more difficult to sinter the monophasic powder to high density in spite of the molecular level homogeneity of this powder. A detailed study on sintering and strength measurements is in progress.

The SEM micrographs of the fracture surfaces of the pellets dry pressed from mono- and diphasic powders and sintered at different temperatures and times are presented in Figs. 10 and 11 , respectively. Large grain growth is evident in the samples fired at $1600{ }^{\circ} \mathrm{C}$ for $400 \mathrm{~min}$.

\section{SUMMARY AND CONCLUSIONS}

The combined results of TGA, DTA, XRD, and IRS present a clear formation sequence for obtaining mullite from either mono- or diphasic xerogels. Monophasic gels crystallize from an amorphous structure to a silicon substituted alumina spinel at temperatures below $1000^{\circ} \mathrm{C}$. The substitution of silicon in the spinel structure is inferred from the sharp crystallization exotherm noted in the DTA results. The spinel phase is metastable and transforms to mullite when held isothermally near the crystallization temperature. The monophasic gel yields a well crystallized mullite with some residual amorphous phase. The amorphous phase is reduced by further reaction 
at higher temperature. The mullite formed initially is deficient in alumina. The composition shifts towards stoichiometry at higher temperatures.

The diphasic materials follow a much different formation sequence. The xerogel is composed of boehmite and a distinct amorphous silica phase. The boehmite decomposes to a cubic alumina spinel structure at low temperature. There is little or no reaction between the spinel and amorphous phases. Mullite is formed by solid state reaction between $\alpha-\mathrm{Al}_{2} \mathrm{O}_{3}$ and cristobalite which form from the spinel and amorphous phases respectively at $1360{ }^{\circ} \mathrm{C}$. The mullite is not well crystallized initially and residual phases remain even after heating at $1600^{\circ} \mathrm{C}$ for $6 \mathrm{hr}$. The mullite is also alumina deficient initially, but the composition shifts towards stoichiometry at higher temperatures. The diphasic powder can be sintered to high densities. Whereas the monophasic powder is much more difficult to densify in spite of its molecular level homogeneity.

Even though the monophasic precursor transforms to mullite at a low temperature, inability to sinter it to high density will limit its use in ceramic composites. The diphasic mullite precursor seems promising as a matrix material. However, methods of densifying it at lower temperatures must be found. Methods of achieving this goal, such as supercritical drying of the gel and improved processing of the precursor powder, are under study.

\section{ACKNOWLEDGMENTS}

The authors wish to thank $L$. Hyatt for performing the TGA, DTA, and IRS and R. Garlick for performing the XRD work.

\section{REFERENCES}

1. K. Okada and N. Otsuka, J. Am. Ceram. Soc. $\underline{\underline{69}}$ (1986) 652 .

2. D.W. Hoffman, R. Roy, and S. Komarneni, ibid. 67 (1984) 468. 
3. M.G.M.U. Ismail, Z. Nakai, and K. Minegishi, Int. J. High Tech. Ceram. $\underline{2}$ (1986) 123.

4. S. Komarneni, R. Roy, C.A. Fyfe, G.J. Kennedy, and H. Strobl, J. Am. Ceram. Soc. $\underline{\underline{69}}(1986)$ C -42 .

5. A.K. Chakraborty and D.K. Ghosh, ibid. 6l (1978) 170.

6. G.W. Brindley and M. Nakahira, ibid. 42 (1959) 311.

7. S. Sen and S. Thiagarajan, Ceram. Int1. 14 (1988) 77.

8. K. Okada and N. Otsuka, J. Am. Ceram. Soc. $\underline{\underline{70}}$ (1987) C-245.

9. K. Wefers and G.M. Bell, "Oxides and Hydroxides of Alumina," Technical Paper No. 19, ALCOA Research Lab, Pittsburgh, PA, 1972.

10. J.A. Gadsden, Infrared Spectra of Minerals and Related Inorganic Compounds (Butterworths, London, 1975) pp. 43,47,53.

11. W.E. Cameron, Am. Ceram. Soc. Bu11. 56 (1977) 1003.

12. K. Okada, Y. Hoshi, and N. Otsuka, J. Mater. Sci. Lett. $\underline{\underline{5}}$ (1986) 1315.

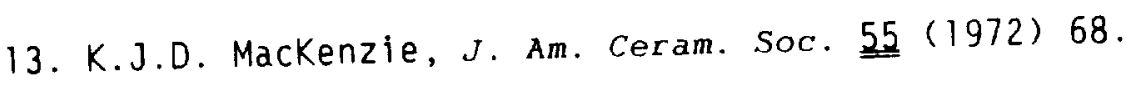




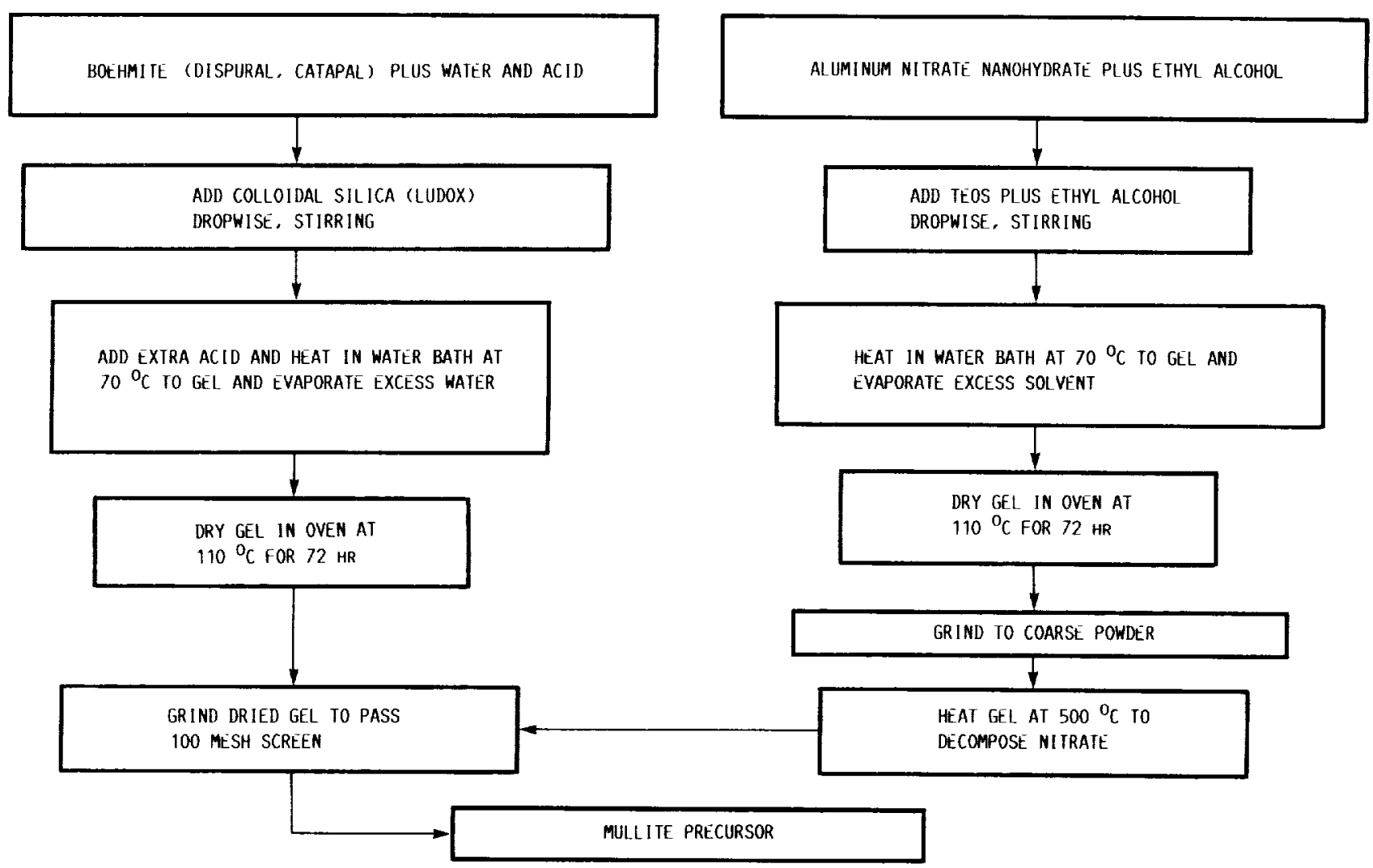

FIGURE 1. - FLOWCHART SHOWING THE SYNTHESIS OF MONOPHASIC AND DIPHASIC MULLIIE PRECURSOR POWDERS.

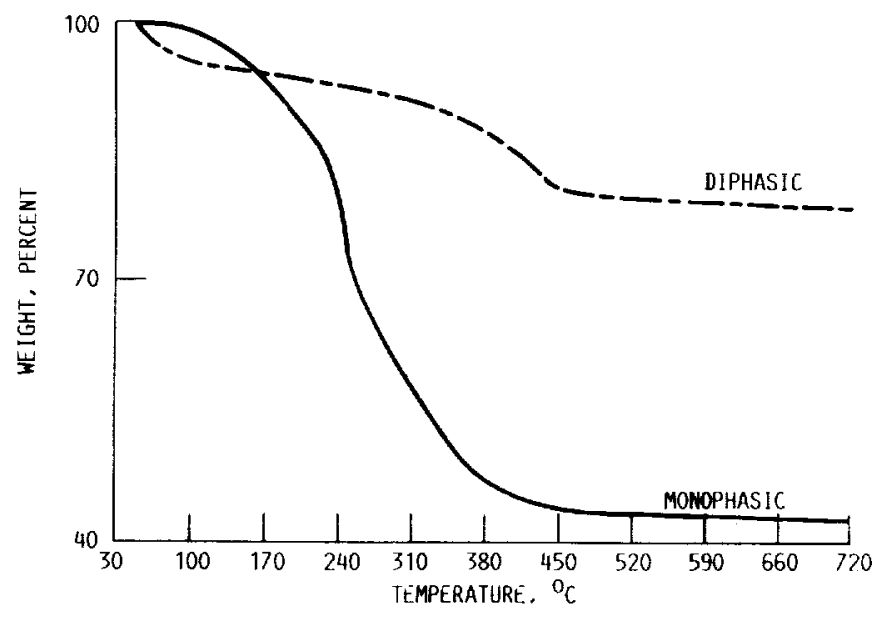

FIGURE 2. - TGA CURVES OF MONOPHASIC AND DIPHASIC GELS OF MULLITE COMPOSITION RECORDED AT $10{ }^{\circ} \mathrm{C} /$ MIN IN FLOWING AIR. 


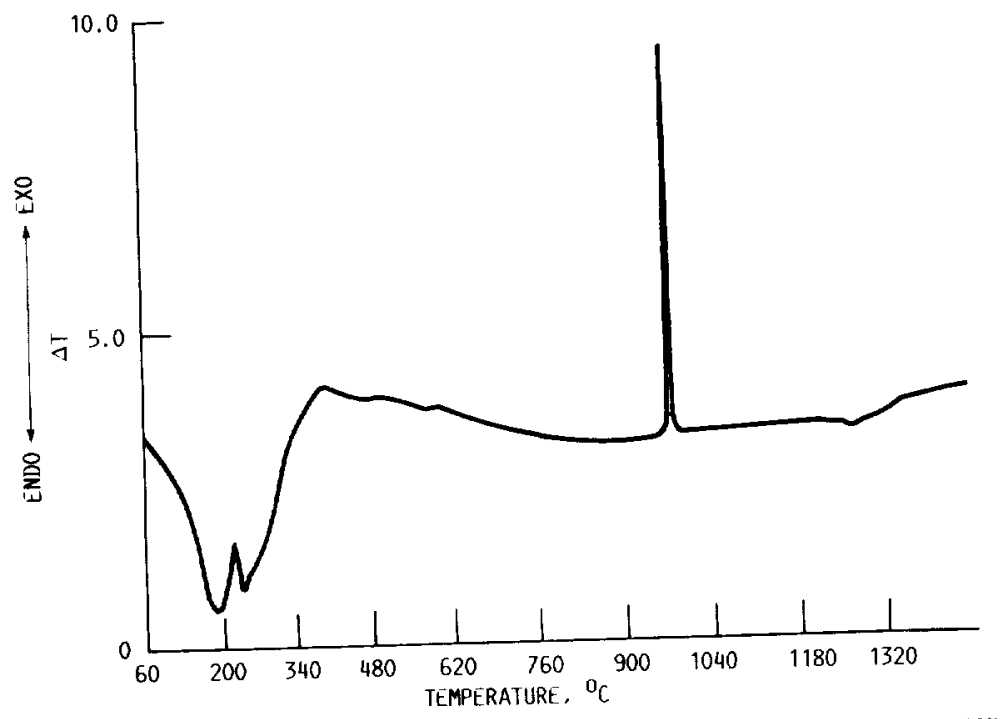

FIGURE 3. - DTA CURVE OF MONOPHASIC GEL POWDER OF MULLIIE COMPOSITION RECORDED AT $10^{\circ} \mathrm{C} /$ MIN IN FLOWING AIR.

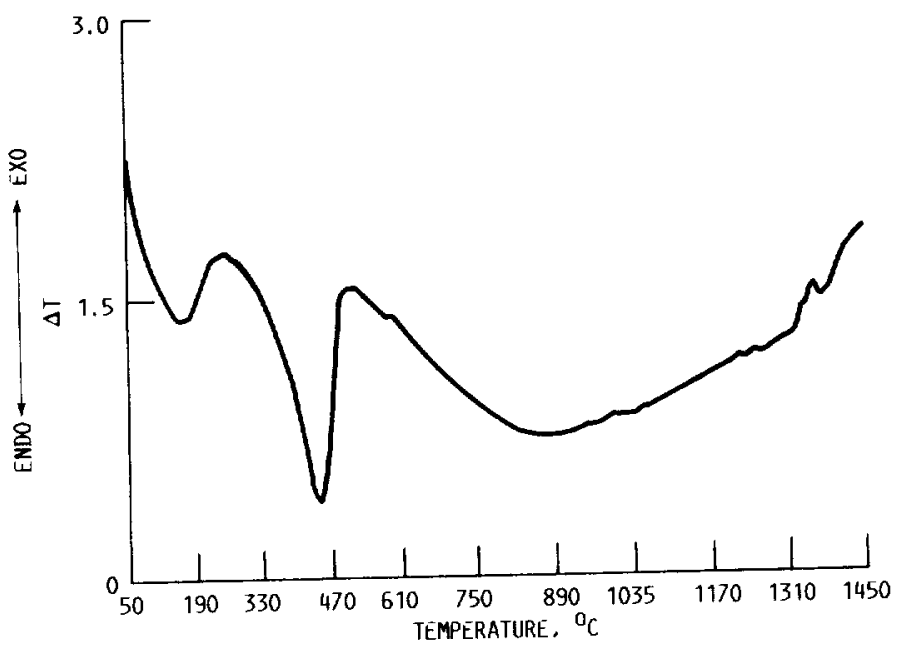

FiguRE 4. - DTA tRACE OF DIPHASIC MULLITE PRECURSOR Gel. POWDER AT $10^{\circ} \mathrm{C} / \mathrm{MIN}$ UNDER FLOWING AIR. 


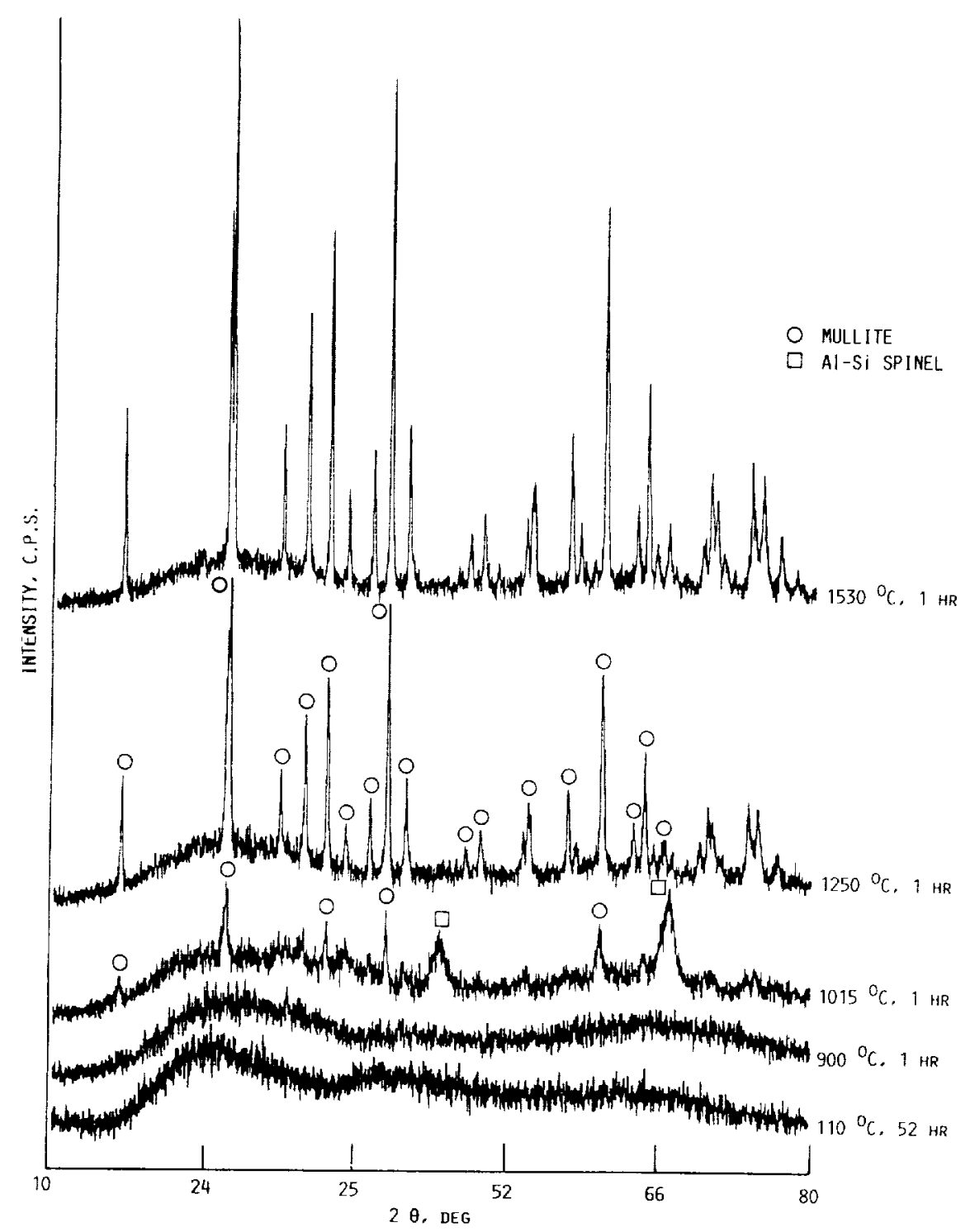

FIGURE 5. - X-RAY DIFFRACTION PATTERNS OF MONOPHASIC MULLIIE PRECURSOR POWDERS AFTER CALCINATION IN AIR AI VARIOUS TEMPERATURES. 


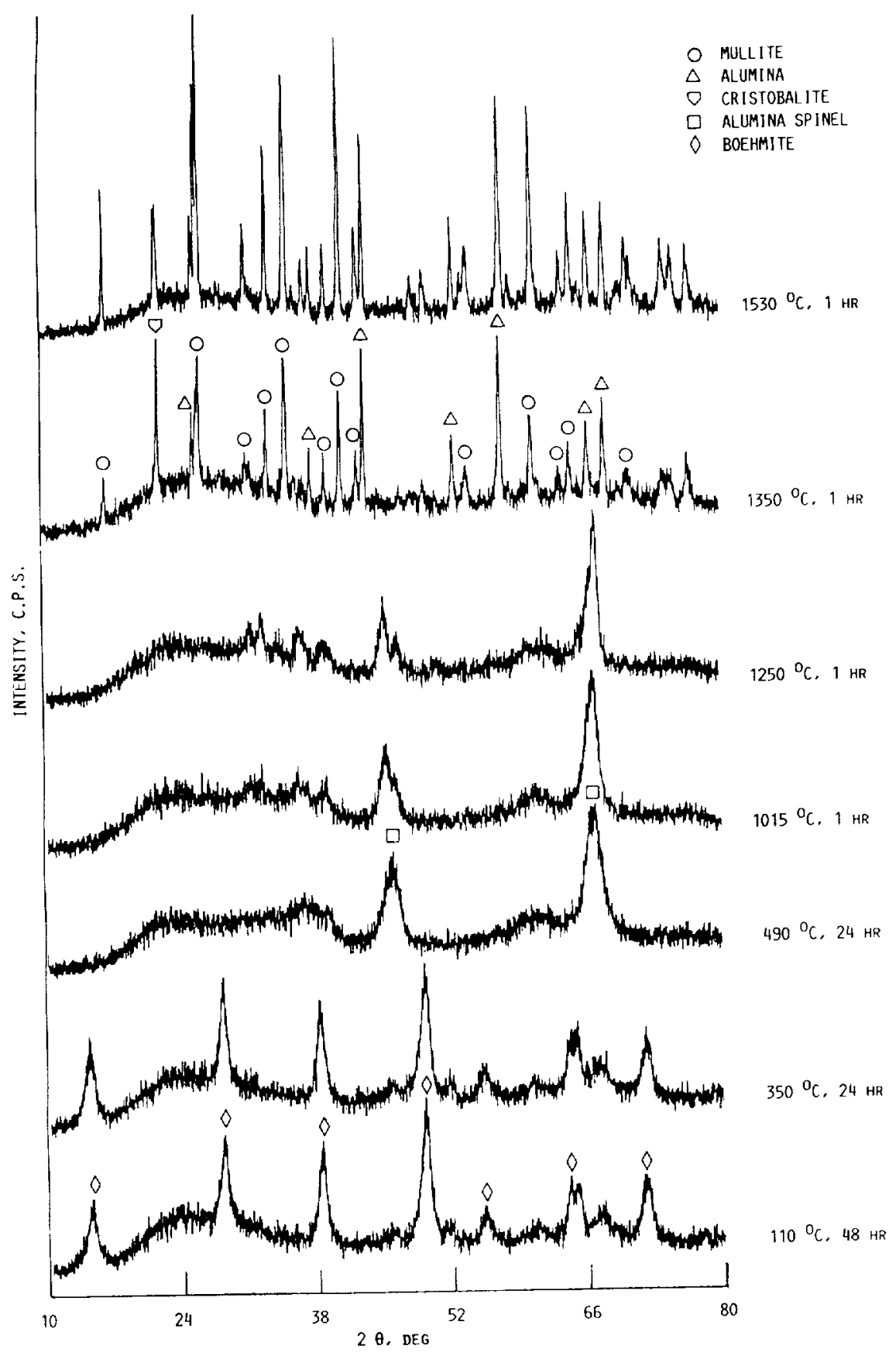

FIGURE 6. - X-RAY DIFFRACTION SPECTRA OF DIPHASIC PRECURSOR POWDER OF MULLIITE COMPOSIIUON AFTER CALCINATION IN AIR AT DIFFERENT IEMPERATURES. 


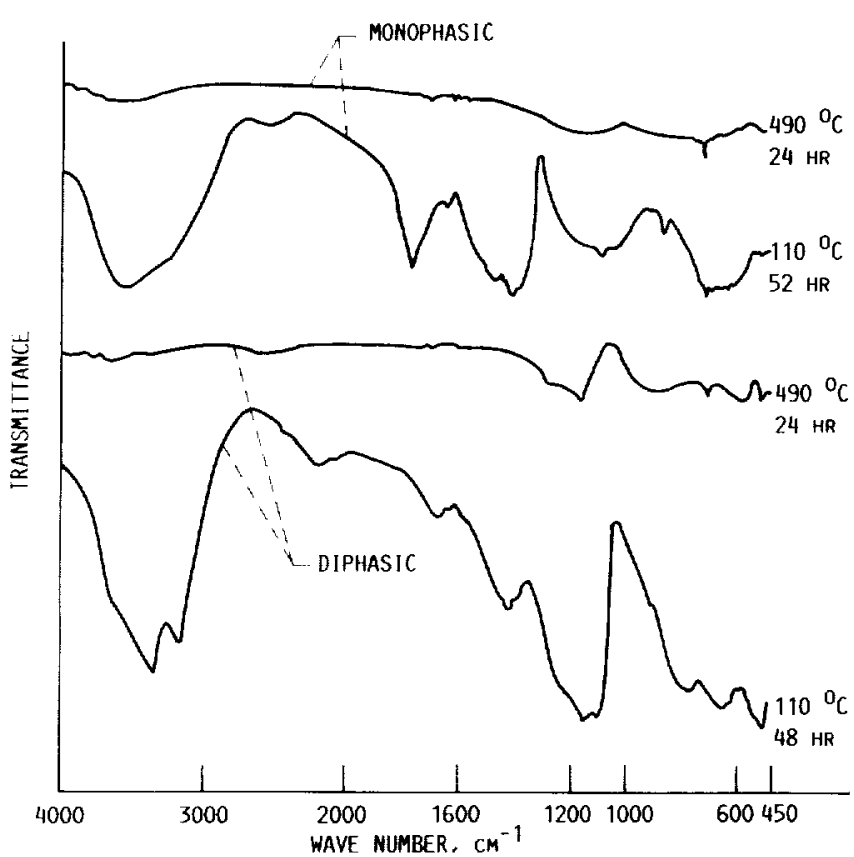

FIGURE 7. - INFRARED SPECTRA OF MONOPHASIC AND DIPHASIC GELS OF MULLITE COMPOSITION AFTER CALCINATION AT 110 AND $490^{\circ} \mathrm{C}$ FOR 24 AND $52 \mathrm{HR}$, RESPECTIVELY.

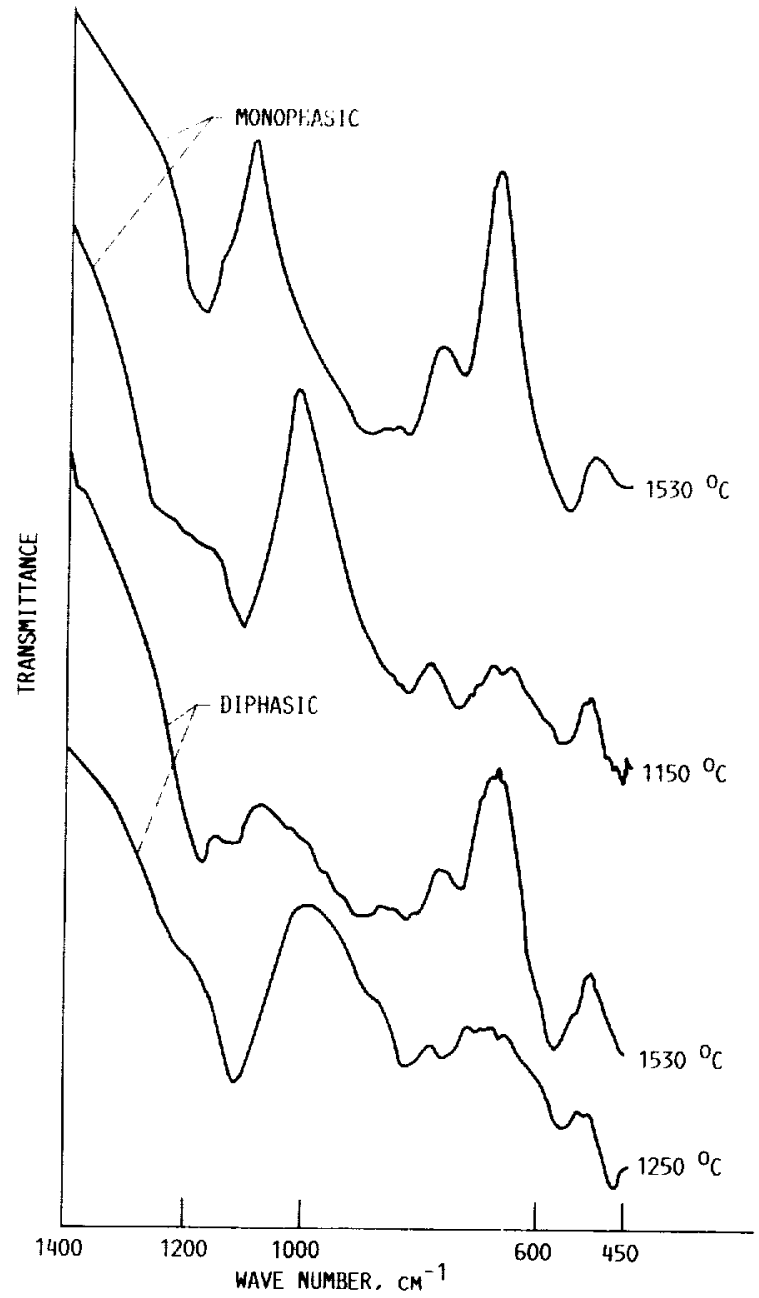

FIGURE 8. - INFRARED SPECIRA OF MONOPHASIC AND DIPHASIC GELS OF MULLITE COMPOSITION AFTER FIRING AT HIGH TEMPERATURES.

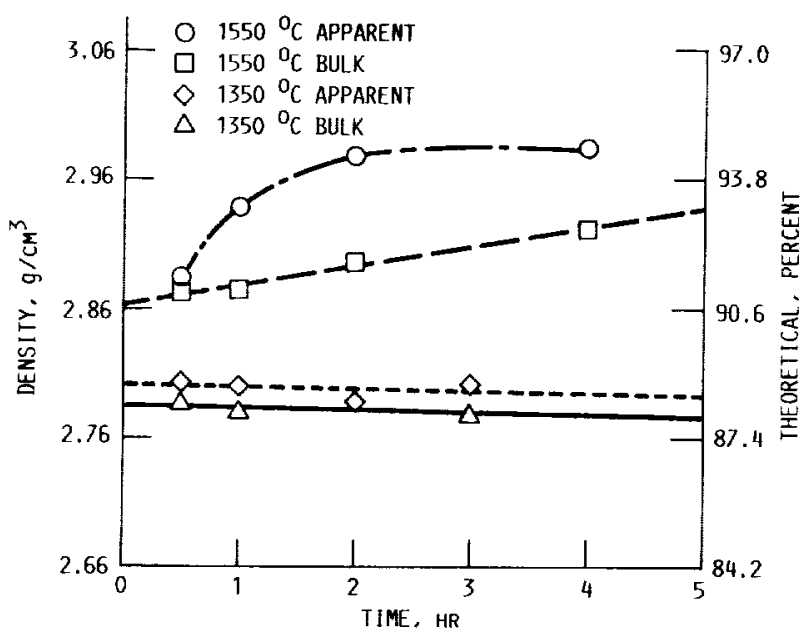

FIGURE 9. - APPARENT AND BULK DENSITIES OF BARS ISOSTATICALLY PRESSED FROM DIPHASIC POWDER OF MULLITE COMPOSITION AND SINTERED AT 1350 AND $1550^{\circ} \mathrm{C}$ FOR DIFFERENT TIMES. EACH POINT IN THE GRAPH REPRESENTS THE AVERAGE DENSITY OF FOUR SINTERED BARS. 


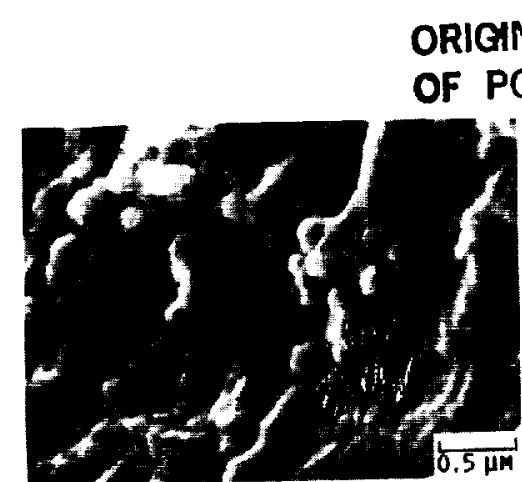

(a) $1200{ }^{\circ} \mathrm{C}$ FOR 100 MIN.

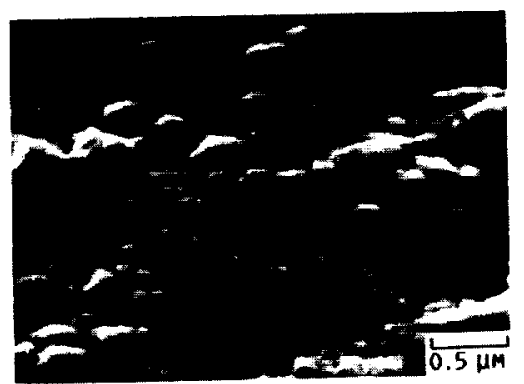

(c) $1600^{\circ} \mathrm{C}$ FOR $100 \mathrm{MIN}$.

ORIGINAL PAGE IS

OF POOR QUALITY

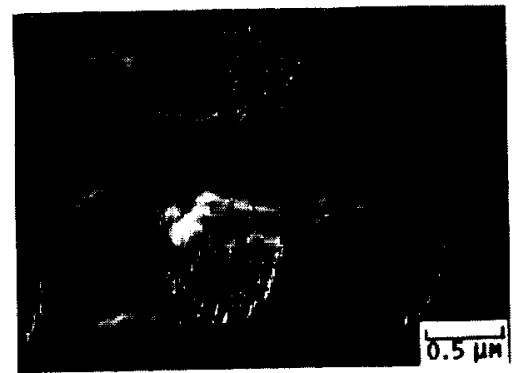

(b) $1400{ }^{\circ} \mathrm{C}$ FOR $100 \mathrm{MIN}$

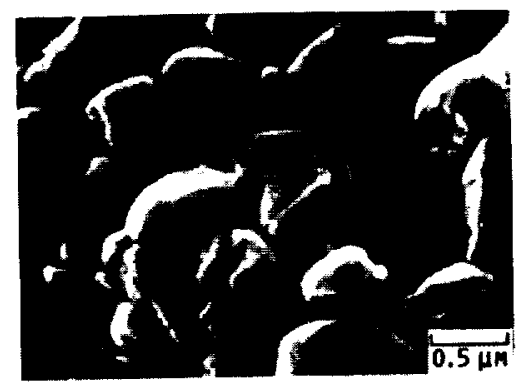

(d) $16000^{\circ} \mathrm{C}$ FOR 400 MIN.

FIGURE 10 - SCANNING ELECTRON MICROGRAPHS OF FRACTURE SURFACES OF DRY PRESSED MONOPHASIC POWDER COMPACIS OF MULI IIE COMPOSITION SINTERED IN AIR.

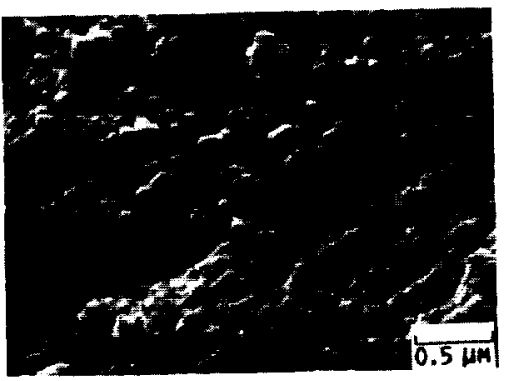

(a) $1200{ }^{\circ} \mathrm{C}$ FOR $100 \mathrm{MIN}$.

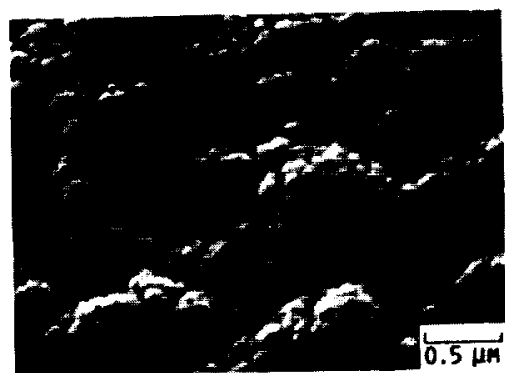

(c) $1600{ }^{\circ} \mathrm{C}$ FOR $100 \mathrm{MIN}$.

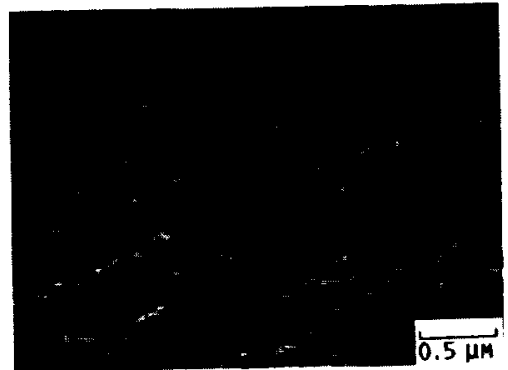

(b) $1400^{\circ} \mathrm{C}$ FOR 100 MIN

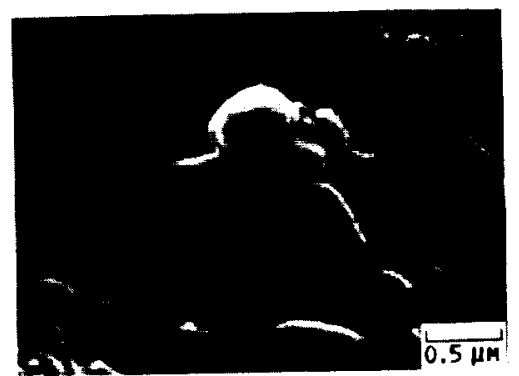

(d) $1600{ }^{\circ} \mathrm{C}$ FOR $400 \mathrm{MIN}$.

FIGURE 11. - SCANNING ELECTRON MICROGRAPHS OF FRACTURE SURFACFS OF DRY PRESSED DIPHASIC POWIER COMPACTS OF MULLIIE COMPOSITION SINTERED IN AIR. 


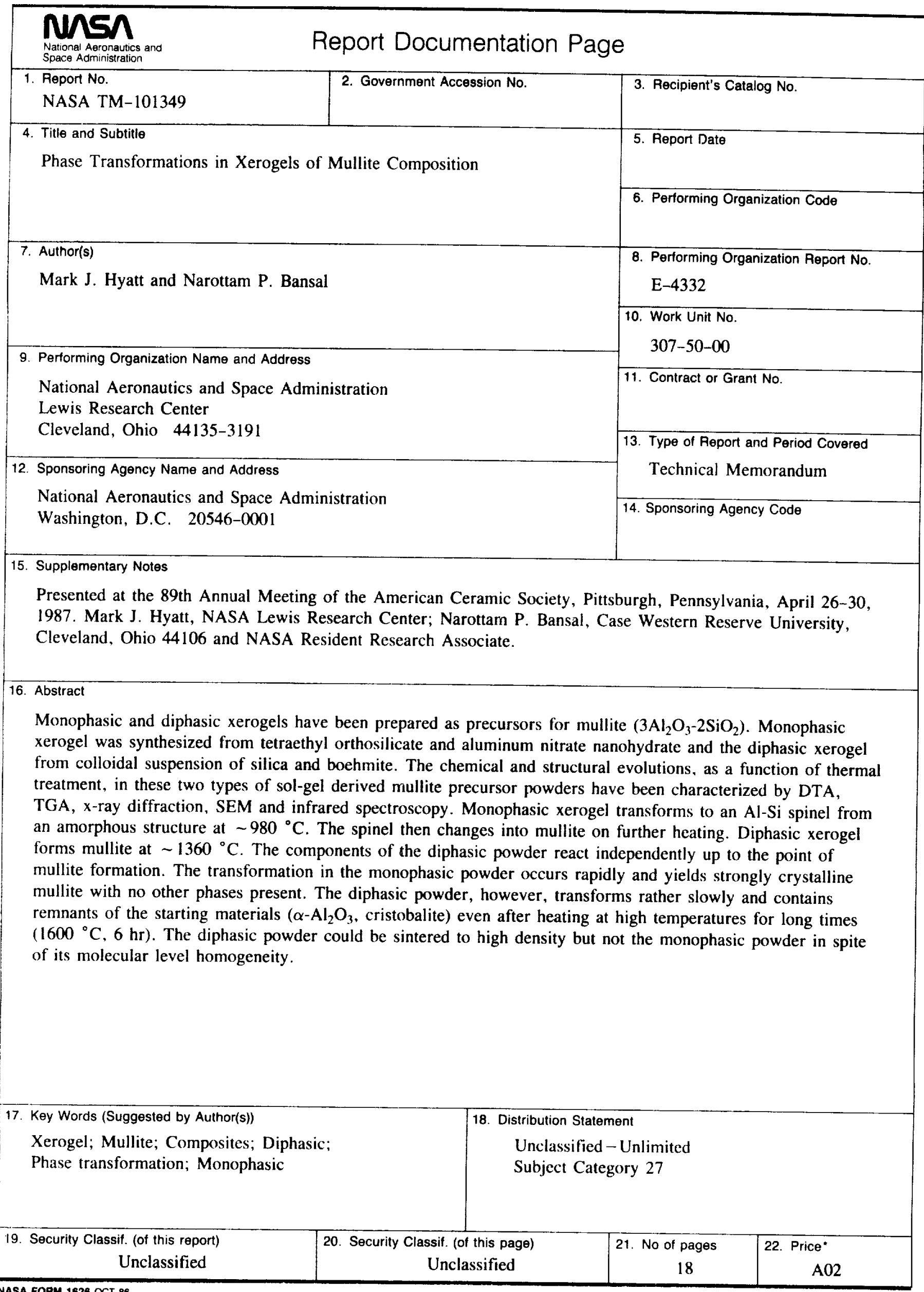



National Aeronautics and

Space Administration

Lewis Research Center

Cleveland. Ohio 44135

Onciel Business

Penalty for Pitvelo Une 5300
SECOND CLASS MAIL

ADDRESS CORRECTION REQUESTEO

Dees Paid

National Aoronautics and

Space Administration

NASA-451 